\title{
Human relaxin-2: historical perspectives and role in cancer biology.
}

\author{
Vinojini B. Nair ${ }^{1,2}$, Chrishan S. Samuel ${ }^{1,3,4}$ Frances Separovic $^{2}$ \\ Mohammed Akhter Hossain ${ }^{1,2 *}$, John D. Wade ${ }^{1,2} *$
}

${ }^{1}$ Florey Neuroscience Institutes, ${ }^{2}$ School of Chemistry, ${ }^{3}$ Department of Biochemistry and Molecular Biology, University of Melbourne, VIC 3010, Australia; ${ }^{4}$ Department of Pharmacology, Monash University, VIC 3800 , Australia

\section{*Corresponding authors:}

Dr Mohammed Akhter Hossain

Florey Neuroscience Institutes, University of Melbourne, VIC 3010, Australia

Phone: +61383447330

Fax: +61393481707

Email: akhter.hossain@florey.edu.au

Professor John D. Wade

Florey Neuroscience Institutes, University of Melbourne, VIC 3010, Australia

Phone: +61383447330

Fax: +6139348 1707

Email: john.wade@ florey.edu.au

Key words: H2 relaxin, relaxin, RXFP1, cancer, tumour development 


\begin{abstract}
:
One of the most recognised and studied family of peptide hormones is the insulin superfamily. Within this family is the relaxin subfamily which comprises seven members: relaxin-1, -2 and -3 and insulin-like (INSL) peptides 3, 4, 5 and 6. Besides exhibiting sequence similarities, each member exists as an active A-B heterodimer linked by three disulfide bonds. This mini-review is divided into three broad themes: an overview of all insulin superfamily members (including structural similarities); roles of each superfamily member and finally, a focus on the pleiotropic peptide hormone, human relaxin-2. In addition to promoting vasodilatory effects leading to evaluation in Phase III clinical trials for the treatment of acute heart failure, relaxin has recently been shown to be highly expressed by cancer cells, aiding in their proliferation, invasiveness and metastasis. These contrary effects of relaxin are discussed together with current efforts in the development of relaxin antagonists that may possess future therapeutic potential for the treatment of certain cancers.
\end{abstract}




\section{INTRODUCTION}

\section{Evolution - insulin and relaxin family of peptides}

In the early 1920s, Frederick Hisaw alongside his then $\mathrm{PhD}$ student, Alexander Albert, and other co-workers observed pelvic ligament softening and broadening in pregnant female guinea pigs, which aided in offspring delivery (Hisaw 1926). Albert sectioned sow corpura lutea and extracted and partially purified the hormone involved in the guinea pigs' interpubic ligament relaxation. Injection of this extracted hormone into virgin guinea pigs induced similar effects as seen in the pregnant guinea pigs. Thus, the hormone was termed "relaxin" (Hisaw 1926; Ziel 2000).

In 1945, Robert Kroc, another of Hisaw's former $\mathrm{PhD}$ students, took on the pioneering role of developing bioassays to enable the structural study of relaxin. Due to obstacles associated with protein-isolating techniques and the difficulty of preparing pure relaxin, the study the physiology and chemistry of relaxin was a challenge (Friedman 2003). It was not until the mid-1970s that improved techniques to isolate and produce large quantities of purified relaxin enabled determination of the first relaxin primary structure (Bathgate et al. 2006a). Relaxin was shown to share remarkable structural conservation with insulin (approximately $25 \%$ structural similarity) in that it consisted of 2 chains held together by three disulfide bonds (Bathgate et al 2006a; Friedman 2003). It was subsequently shown that like insulin, relaxin was also synthesised initially as a single chain pre-prohormone (Sherwood and O'Byrne 1974). Today, with the advancement of DNA sequencing and genomic database searching technologies, primary structures of relaxin from more than twenty different species have been determined (Bathgate et al. 2006).

Further studies have shown that there are several other insulin-like peptides in the genome. These make up what is now known as the insulin superfamily. Within this family, the relaxin subfamily consists of two main groups, the insulin-like peptides (INSL3, 4, 5 and 6) and relaxins (relaxin-1,-2 and -3) (Park et al. 2005) as shown in Figure 1. While the evolutionary pattern and partial sequence homology between the relaxin-1 (RLN1) and -2 (RLN2) genes suggest some similarities between them (Kong 2010), subsequent studies have shown that the RLN1 gene is in fact a pseudo-gene that does not get translated into a functional protein (Bathgate et al. 2006a); while the RLN2 gene encodes the major stored and circulating form of relaxin in humans. Interestingly, lower primates and rodents lack an orthologue of the RLN1 gene, but contain the RLX and RLX3 genes, which encode for relaxin and relaxin-3; the species-equivalent of human relaxin-2 and relaxin-3 (Wilkinson 2005), respectively. Like human relaxin-2, the equivalent relaxin peptide in other species represents the major stored and detectable form. For the purposes of this review, genes expressed in the human are systematically named as RLN and those expressed in other species termed RL $\underline{X}$ (Bathgate et al. 2006a; Wilkinson 2005).

\section{Overview - relaxin family structures}

The principal reason members of relaxin family were classified within the insulin superfamily is because of the structural similarities between the two (Figure 2). Furthermore, there is clear evidence towards the evolution of relaxin from early vertebrates from an ancestral insulin gene (Bathgate et al. 2006).

Like insulin, relaxin is initially synthesised on the ribosome as an immature pre-prohormone, prorelaxin, as a single chain structure attached to an N-terminal signal sequence (Bathgate et al. 2006) (Figure 3). The signal sequence directs the transport of the peptide from the ribosomal ubiquitins. Following the loss of signal peptide, the pre-prohormone is converted to a prohormone via co-translational modifications. Proteolytic cleavage of $\mathrm{C}$ chain then yields the A- and B- chain combination, forming mature, active 2-chain heterodimeric peptide. In this two-chain structure, the A- and B-chains are cross-linked by three disulfide bonds with two linking both A- and B-chains and an intra-chain disulfide bond within the A-chain (Bathgate et al. 2006; Liu et al. 2003). With the exception of INSL3, these post-translational modifications remain to be confirmed for members of the INSL family (Büllesbach and Schwabe 2002).

The amino acid sequences of all relaxin family members have been determined by DNA recombinant technologies. Little homology is observed amongst the members with the only invariant residues being the 
cysteines across both A- and B- chains making up the disulfide bonds and a single glycine within the B-chains. These non-conserved regions have been implicated in the various roles and receptor binding abilities of each relaxin family member. For human relaxin-2, despite its established role as a multi-functioning hormone, the first crystal structure of this pleiotropic hormone was determined and published only in the early 1990's (Eigenbrot e al. 1991).

\section{Receptors - Relaxin Family Peptide Receptors (RXFPs)}

Peptides within the relaxin family interact with G-protein coupled receptors (GPCRs), the biggest class of receptors found in humans. Relaxins-1 (chemically synthesised from its annotated sequence) and -2 can bind and activate leucine-rich repeats containing LGR7 while INSL3 binds and activates LGR8 (Hsu et al. 2002; Kumagai et al. 2002). Following characterization, these two receptors were later termed Relaxin Family Peptides Receptor 1 (RXFP1) and 2 (RXFP2), respectively, by the International Union of Pharmacology (Bathgate 2006a). Structurally, both receptors are more than $50 \%$ similar sequentially and contain a seventransmembrane spanning domain and ectodomains comprising low density lipoproteins Class A (LDL-A) at the N-terminus. These structures contain leucine rich repeats (LRR), which act as the primary binding site for relaxin and connect the seven transmembrane spanning domain to the ectodomain. Relaxin-3 and INSL-5 bind to GPCR135 (now referred to as RXFP3) and GPCR 142 (RXFP4), respectively (Liu and Lovenberg 2008; Zhu 2008). These latter two receptors lack the ectodomain region, LRR, and LDL-A modules. Activation of RXFP1 and RXFP2 results in intracellular cAMP production, via receptor coupling to $\mathrm{G} \alpha_{\mathrm{S}}$ and $\mathrm{G} \alpha \mathrm{o}_{\mathrm{S}}$. In contrast, RXFP3 and RXFP4 activation leads to inhibition of cAMP production due to downward actions of inhibitory $\mathrm{G}$ proteins (Lu et al. 2006; Lin 2004).

Due to the structural similarity of peptides within the relaxin superfamily, cross activation of non-native receptors does exist. For example, relaxin-3 has been shown to bind and activate RXFP1 (Bathgate et al. 2006b; Hossain et al. 2011; Zhang et al. 2012) and RXFP4 as well as its native receptor, RXFP3. Likewise, relaxin-2 binds to and activates RXFP2, the native INSL3 receptor (Sherwood 2004).

\section{RELAXIN PEPTIDE SUBFAMILY MEMBERS - ROLES AND THERAPEUTIC APPLICATIONS}

\section{Insulin-Like Peptides (INSLs)}

INSL3 has been implicated as having reproductive and non-reproductive roles. In male rats, INSL3 has been shown to prevent male germ cells from entering the apoptosis stage of the cell cycle (Kawamura et al. 2004). Additionally, the previously termed Leydig cell insulin-like peptides (Adham et al. 1993) are produced by foetal Leydig cells and are involved in testicular descent via the growth of gubernacular ligament (Ivell et al. 2005). In females, INSL3 is also implicated in a similar anti-apoptotic role, especially in ovarian follicles and thecal cells, during the follicle selection processes (Kawamura et al. 2004; Ferlin et al. 2009). INSL3 antagonists are thus expected to be potential male and female contraceptive agents (Shabanpoor et al. 2010).

The fetal perichondrium and cytotrophoblasts have been shown to express INSL4, and accounts for it also being known as Early Placenta Insulin-Like Peptide (Bellet et al. 1997). Similar to the other members of this superfamily, INSL4 is expressed as a $15 \mathrm{kDa}$ precursor, which then undergoes cleavage to form its tertiary structure (either two or three chain structures) (Büllesbach and Schwabe 2001). INSL4 has been implicated in being involved in trophoblastic development, including early cell proliferation and development (Laurent et al. 1998). Despite being exclusive to higher primates, the exact signal transduction and physiological role of INSL4 remain unknown.

Examination of the expressed sequence tags databases resulted in the discovery of a novel insulin-like sequence, termed INSL5. The primary physiological function of INSL5 remains unknown but recent studies imply it may play a role in appetite control and gut motility (Belgi et al. 2011). The peptide has been produced by both chemical synthesis and recombinant DNA expression (Hossain et al. 2008, Luo et al 2010) which, in turn, is aiding the identification of its functional roles. 
Another member of this ancient superfamily of functionally diverse peptide hormones is INSL6. It is predominantly expressed in the primary reproductive male organ, the testis. However, published results do not concur regarding the specific cell type expressing INSL6. For example, studies by Hsu (Hsu 1999) concluded INSL6 is expressed in Leydig cells but studies by Lok et al. (Lok et al. 2000) established expression in spermatids but none in Leydig cells. Despite this discordance, INSL6 has been shown to be heavily involved in progression of spermatogenesis (Lu 2006). Further research is required to identify the specific receptor for INSL6 and its exact physiological chemistry.

\section{Relaxin}

Despite having two peptide-coding genes, relaxin gene 1 (RLN1) and RLN2, the major stored and circulatory form of relaxin in humans is relaxin-2. Relaxin-2 is produced in the prostate by males (Feng and Agoulnik 2007) and corpus lutea in females (Shabanpoor et al. 2009). Since relaxin-1 is a pseudogene, which does not translate into a functional peptide in rodents, humans and other non-human species, both relaxin-1 and -2 will be referred to as relaxin here forth.

As mentioned previously, relaxin is the most comprehensively studied member of the relaxin subfamily. Structure-activity studies of relaxin have revealed the receptor "binding cassette" of this multi-functional peptide hormone lies within its $\mathrm{B}$-chain $\left(\mathrm{Arg}_{13} \mathrm{X}-\mathrm{X}-\mathrm{X}-\mathrm{Arg}_{17} \mathrm{X}-\mathrm{X}-\mathrm{Ile}_{20}\right)$ and interacts with the binding pocket in native receptor, RXFP1. Büllesbach $e t$ al. have shown the importance of the binding cassette by replacing the arginine at position 13 and 17 with citrulline, lysine and alanine, rendering inactive the relaxin native receptor (no interaction with RXFP1) (Büllesbach and Schwabe 2000). $\operatorname{Arg}_{13}$ and $\operatorname{Arg}_{17}$ residues on the B-chain of relaxin interact with a network of two aspartic acid/glutamic acid pairs in the LRR within the ectodomain of its native receptor, RXFP1. In addition, the $\mathrm{Il}_{20}$ residue on the relaxin B-chain interacts with tryptophanisoleucine-leucine region of the LRR. Non-specific binding is observed on deletion of any of the aforementioned three residues on the ligand (Büllesbach and Schwabe 2000; Hossain and Wade 2010).

The effect of relaxin, particularly during pregnancy, is well established in rodents. Levels of relaxin change with the different stages of pregnancy and these patterns are dissimilar across species. In rodents, sows and dogs, relaxin is untraceable early in the gestation but increases and reaches a maximum before labour (Hwang 1989; Johnson 1991). Conversely, maximum circulating relaxin is observed in humans within the first trimester of pregnancy. Plasma relaxin then reduces and somewhat plateaued for the remaining period of pregnancy, almost in a contrary pattern to rodents, sows and dogs (Burger et al. 1998; Eppel et al. 1999). As mentioned earlier, the main source of circulating relaxin is from the corpus luteum in females (Shabanpoor et al. 2009) and has been shown to aid in embryo implantation via uterine vascularisation and differentiation of endometrial cells (Eppel et al.1999). Besides aiding in pelvic ligament and cervical softening of birth canals, relaxin has been shown to be involved in remodelling and development of mammary glands and nipples of mice (O'Day et al. 1989).

Furthermore, relaxin has been shown to increase oocytes fertility (Brener et al. 1984). Besides exerting its effect in female reproduction, relaxin is also involved in maintaining sperm motility in the male reproductive system (Weiss 1989). This conclusion was drawn when increased penetration was observed in human cervical mucous for human sperm incubated with porcine relaxin compared to buffer mixture (Weiss et al. 1989; Pupula et al. 1986). These exciting findings point to the therapeutic potential of relaxin towards assisting with infertility in humans.

Relaxin has also been shown to be involved in non-reproductive functions. For example, relaxin plays a crucial role in cardiovascular and renal systems (Conrad et al. 2004). Relaxin promotes collagen breakdown in systemic tissues (Unemori 1990), rendering a high possibility for an ability to reduce systemic fibrosis (Unemori et al. 1996; Samuel 2005). Fibrosis occurs when collagens, glycoproteins and other extracellular matrix accumulate in organs. When relaxin is introduced to systemic organs such as the heart and lungs, over-expression of collagen has been reduced (Samuel et al. 2004). Moreover, relaxin has also been observed to increase vasodilation and renal functions in pregnant females. This, along with its cardioprotective actions (Dschietzig et al. 2006; Samuel 
et al. 2006) has led to efforts to exploit its haemodynamic roles and consequently relaxin is currently in Phase III clinical trials for the treatment of acute heart failure. The clinical trials to date have demonstrated relaxin provided relief of dyspnoea (symptom of breathlessness) and reduction of heart failure symptoms (Teerlink et al. 2009).

\section{Relaxin-3}

Relaxin-3 exerts its actions through its native receptor, RXFP3, which is found in the hypothalamic paraventricular nucleus of the brain. The expression site of this most recently discovered insulin superfamily neuropeptide was found to be in the nucleus incertus within the hypothalamus. These regions of the brain have been extensively associated with regulation of energy homeostasis and appetite regulation (McGowan et al. 2005). Additionally, the paraventricular nucleus plays a reproductive role during reproduction by providing feedback to the hypothalamic gonadotrophin-releasing hormone neurons (Chan et al. 2011). Interestingly, relaxin-3 knockout mice have shown altered sleep patterns during normal active (night) periods with increased sleep episodes compared to their wildtype counterparts (Ma and Gundlach 2007). Although the exact physiological mechanisms of relaxin-3 in humans still remain vague, studies from rodents have suggested that relaxin-3 may coordinate sleep, hunger and food intake regulation, (Chan et al. 2011; Ma and Gundlach 2007) which make the developments of relaxin-3/RXFP3 agonists and antagonists desirable therapeutic candidates.

\section{RELAXIN AND ITS POTENTIAL ROLE IN CANCER BIOLOGY}

While well known for its reproductive and antifibrotic roles, most recently relaxin has been associated with cancer biology. A number of putative roles, including the modulation of tumor growth, neovascularization, metastasis and oncogenic progression, have been correlated to relaxin overexpression (Silvertown et al. 2003). The following sections will focus on the effects of downstream intracellular relaxin signaling and its physiological implications.

\section{Intracellular pathways associated with cancer biology known to be activated by relaxin}

In addition to its vasodilatory effects, relaxin has been shown to promote nitric oxide (NO) production in renal, cardiac and hepatic systems. In MCF-7 breast cancer cell lines, production of NO was reported to be increased via heightened nitric oxide synthase (iNOS) production (Failli et al. 2002; Bani et al. 1999b). Increased NO production is implicated with oncogenic cell migration and growth (Bani et al. 1995; Jadeski et al. 2003). As highlighted above, relaxin stimulates increased vasodilation in a range of systemic tissues, including the skeletal and cardiac muscles. Relaxin-induced NO production could possibly encourage blood flow and growth of new blood vessels (angiogenesis) in the MCF-7 mammary cancer cell line. NO encourages cell apoptosis by inhibiting DNA synthesis and mitochondrial respiration, decreasing rate of cellular growth and multiplication (Jadeski et al. 2000). However, studies have shown increased expression of iNOS in an adenocarcinomic breast cancer cell line, MCF-7, incubated with porcine relaxin. These observations may correlate with relaxin assisting cancer cells avoid to apoptosis. This could lead to further invasiveness and metastasis potential, particularly with malignant oncogenic cells (Bani et al. 1995; Jadeski et al. 2000). Further studies investigating the relationship of increased NO production and its impact on oncogenic acceleration may be useful in understanding the role of relaxin in cancer.

\section{The influence of relaxin in cell growth, invasion and angiogenesis}

Besides its inherent biochemical signalling pathway, other physiological roles of relaxin may also encourage tumour advancement, further aggravating the severity of cancer. Cancer progression involves oncogenic cell replication, development (tumerogenesis) and spread of the tumour mass from one organ or tissue to another (metastasis). All of these physiological actions involve angiogenesis and tissue growth, remodelling and apoptosis (Failli et al. 2002). These oncogenic "hallmarks" are closely related to one another despite being classified as three separate physiological events - cell growth, cell invasion and angiogenesis. These three events can be seen in two gender-specific leaders in oncogenic mortality: prostate cancer and breast cancer. The following sections address these "hallmarks" and their consequential effects. 


\section{Relaxin and prostate cancer}

The unresponsive state of uncontrolled cell division and differentiation is a characteristic feature of cancer cells. As previously mentioned, further growths of tumours are aided by vascularisation due to over-expression of NO. The changes observed in matrix metalloproteases contribute to changes in the underlying framework of connective tissues - this increased angiogenesis and changes in connective tissue framework are classic giveaways of relaxin-mediated effects (Hansell et al. 1991; Samuel et al. 2004; Bathgate et al. 2006). Early studies which focus on causatives of neoplastic prostatic cells, particularly abnormal cell increase, conclude peptides may also be involved in hyperplasia (Ivell et al. 1989; Sokol et al. 1989) as well as steroid hormones (Montie and Pienta 1994).

The state of hyperplasia was indicated by angiogenesis and remodelling of the connective tissue framework. Furthermore, marked uncontrolled rate of cell differentiation is another indication of the aforementioned neoplastic prostatic cells observed in men and male dogs (Barrett-Connor et al. 1990; Nomura et al. 1988). Both observations are classic, trademark effects of relaxin (Bathgate et al. 2006). Furthermore, a study has shown a human prostate adenocarcinoma cell line, LNCaP, to express high levels of a relaxin mRNA, FGC. These findings were observed via reverse transcription PCR and Northern blot analysis. This may be reflective in vivo as besides being a product of the RLN2 gene, relaxin found in the seminal fluid is expressed by the prostate gland (Gunnersen 1995). The high levels of mRNA transcripts suggest a link to prostate cancer. Increased neoplastic prostate xenografts have been shown to be due to lentiviral-mediated relaxin delivery into PC-3 prostate cancer cell line (Silvertown 2006) and an R273H p53 mutation directly targets downstream relaxin production in prostatic carcinoma cells (Vinall et al. 2006).

\section{Relaxin and breast cancer}

Similar to its effects on prostate cancer cell lines, relaxin is associated with impairment in the development of mammary cells, leading to neoplastic mammary tissues (Bani et al. 1984; Binder et al. 2001). Elevated relaxin transcripts in neoplastic mammary tissues compared to non-neoplastic tissues were reported in 1994 (Sacchi et al. 1994). Increased circulating relaxin levels were also observed in women diagnosed with breast cancer (Binder et al. 2004). The canine relaxin precursor, prorelaxin 2, has been shown to increase invasiveness of canine mammary cells (Silvertown et al. 2003). In rodents, relaxin has been shown to encourage replication and differentiation of mammary cells, particularly glands responsible for milk delivery post-gestation (Min and Sherwood 1996; Winn et al. 1994). Similarly, relaxin in human mammary cells carries out comparable roles alongside oestrogen and progesterone (Bani et al. 1984). The presence of relaxin has been demonstrated in all malignant and benign mammary cell samples in comparison to equivalent cells with normal cell proliferation rate, correlating with elevated circulating relaxin levels amongst metastatic breast cancer patients (Binder et al. 2001). Studies which focus on in vitro aetiology of mammary adenocarcinogenic mammary cells, show low amounts of relaxin encourage cell metastasis over a short time (Sacchi et al. 1994; Bani et al. 1999a). An independent study determined higher relaxin plasma concentration amongst metastatic breast cancer patients, correlating with the previous observation (Binder et al. Et al. 2004).

Despite prostate and breast cancers being the "focus" of most studies, relaxin has been shown to be associated with other types of cancers in vitro including gastrointestinal tract, colorectum, thyroid and endometrial cancer cells (Kamat 2006; Hombach-Klonisch et al. 2006). Most of these cancers have been shown to increase matrix metalloprotease activity (Binder et al. 2002). This causes downstream expression of vascular endothelial growth factors which have been previously shown to increase tumour vascularisation and angiogenesis (Liang et al. 2006).

\section{POTENTIAL THERAPEUTICS TOWARDS RELAXIN-INDUCED CANCER}

Relaxin expression interference in vitro successfully reduced metastasis which led to increased prostate adenocarcinoma cells death (Feng et al. 2007). This particular study was aimed at observing the hallmark characteristics of prostate adenoma: invasion and metastasis rate of prostate cancer cells. Suppression of relaxin levels or reducing the autocrine/paracrine signalling to its native receptor, RXFP1, via short interfering RNAs 
(siRNA) significantly reduced prostate cancer cell growth and metastasis. Moreover, prostate cancer cell apoptosis was also increased with the suppression of relaxin. These observations highlight the importance of relaxin signalling and its role in cancer cells development (Feng et al. 2007).

\section{Relaxin antagonists}

Encouragingly, studies have shown that reducing levels of relaxin and/or its available receptor, RXFP1, in prostate cancer cells reduced metastasis and invasiveness in vitro (Feng et al. 2007; Willcox and Summerlee 2010). Silvertown et al. first showed that lentivirally-produced B-R13/17K H2 relaxin demonstrated antagonistic properties in in vitro studies and successfully impaired prostate cancer xenografts in vivo (Silvertown et al. 2007). This relaxin analogue had two arginines ( $\operatorname{Arg}_{13}$ and $\operatorname{Arg}_{17}$ ) in its B-chain substituted by lysines. The antagonist peptide used in the study was from a lentiviral construct designed to produce pro-BR13/17K H2 relaxin. Despite demonstrating its antagonistic properties, the active, heterodimeric peptide was not chemically characterised and full proteolytic cleavage of the $\mathrm{C}$-chain from the prohormone was not demonstrated. Relaxin peptides with their C-chain intact have previously been shown to retain full activity (Bathgate et al. 2006). Hence, another study soon followed with extensive chemical characterisation of the chemically synthesised and characterised B-R13/17K H2 relaxin (Hossain et al. 2010). The relaxin analogue was synthesised via solid phase peptide synthesis. The latter study confirmed the antagonising ability of the BR13/17K H2 peptide towards the relaxin native receptor (Hossain et al. 2010). These two initial studies on the progression of prostate cancer in vivo and in vitro led to the development of molecular agents (as illustrated in Figure 4) that may aid further understanding of the roles of relaxin in prostate cancer cells. Importantly, the studies of Silvertown et al. (Silvertown et al. 2007) and Hossain et al. have highlighted the need for simpler and efficient relaxin antagonists to effectively reduce metastasis, potentially leading to prospective therapeutic agents (Hossain et al. 2010).

On the other hand, ligand suppression via relaxin antagonists might not be the only approach towards the development of potential therapeutics. An alternative strategy towards an RXFP1 antagonist could be the use of LDL-A module with the aim of relaxin signalling suppression (Feng et al. 2011). This study has successfully shown that the over-expression of the LDL-A module on RXFP1 inhibited downward signalling abilities of the native relaxin receptor on prostate cancer cells, PC3, ultimately providing an unconventional approach towards cancer therapeutics (Feng et al. 2011). However, any RXFP1 antagonist will obviously require careful development to target its anti-tumorogenesis effect without ameliorating the positive actions of relaxin itself. Yet there is little doubt that such compounds represent exciting potential additions to the armoury of clinical treatments towards RXFP1-responsive cancers.

\section{CONCLUSION}

The role of relaxin and its involvement in cancer cell proliferation, metastasis and cell invasion have been proven by numerous studies, further reinforcing its function as a pleiotropic peptide hormone in humans. Three independent studies have concluded that reduction of relaxin production significantly reduces oncogenic progression in vitro and in vivo (Feng et al. 2007), particularly with the aid of a relaxin antagonist (Hossain 2010; Silvertown 2007). These exciting findings illustrate the need for further study of relaxin and its role in cancer biology. In turn, this may improve the afore-mentioned anti-relaxin agent and lead to greater investigation of tumour development and cancers related to relaxin.

\section{ACKNOWLEDGEMENTS}

V.B.N. is a recipient of a Melbourne Research Scholarship by the University of Melbourne; C. S. S. is supported by a National Heart Foundation of Australia and National Health \& Medical Research Council (NHMRC) of Australia RD Wright Fellowship; M.A.H was the recipient of Reid Trust and Florey Foundation Trust Fellowships and J.D.W is an NHMRC Principal Research Fellow. Some of the authors' research reported in this review was supported by NHMRC Project grants 508995 and 1023078. Research at the FNI was supported by the Victorian Government's Operational Infrastructure Support Program. 
CONFLICT OF INTEREST

The authors declare that they have no conflict of interest. 


\section{REFERENCES}

Adham IM, Burkhardt E, Benahmed M (1993) Cloning of a cDNA for a novel insulin-like peptide of the testicular Leydig cells. J Biol Chem 268:26668-26672

Bani D, Masini E, Bello MG, Bigazzi M, Sacchi TB (1995) Relaxin activates the L-arginine-nitric oxide pathway in human breast cancer cells. Cancer Res 55:5272-5275

Bani D, Flagiello D, Poupon MF, Nistri S, Poirson-Birhcat F, Bigazzi, M, Bani G, Sacchi TB (1999a) Relaxin promotes differentiation of human breast cancer cells MCF-7 transplanted into nude mice. Virchows Archiv 435:509-519. doi:10.1007/s004280050435

Bani D, Baccari MC, Nistri S, Calamai F, Bigazzi M, Sacchi TB (1999b) Relaxin up-regulates the nitric oxide biosynthetic pathway in the mouse uterus: involvement in the inhibition of myometrial contractility. Endocrinology 140:4434-4441. doi:10.1210/en.140.10.4434

Bani G, Bigazzi M (1984) Morphological changes induced in mouse mammary gland by porcine and human relaxin. Acta Anat 119:149-154

Barrett-Connor E, Garland C, McPhillips JB, Khaw KT, Wingard DL (1990) A prospective, populationbased study of androstenedione, estrogens, and prostatic cancer. Cancer Res 50:169-173

Bathgate R, Hsueh A, Sherwood OD (2006) Physiology and molecular biology of the relaxin peptide family. In: Neill JD (ed) Knobil and Neill's Physiology of Reproduction, $3^{\text {rd }}$ edn. Academic Press, San Diego, pp 679-768

Bathgate RAD, Ivell R, Sanborn BM, Sherwood OD, Summers RJ (2006a) International Union of Pharmacology LVII: recommendations for the nomenclature of receptors for relaxin family peptides. Pharmacol Rev 58:7-31. doi:10.1124/pr.58.1.9

Bathgate RAD (2006b) Relaxin-3: Improved synthesis strategy and demonstration of its high-affinity interaction with the relaxin receptor LGR7 both in vitro and in vivo. Biochemistry 45:1043-1053. doi:10.1021/bi052233e

Belgi AH, M. A.; Shabanpoor, F.; Zhang, S.; Bathgate, R. A. D.; Tregear, G. W.; Wade, J. D. (2011) Structure and function relationship of murine insulin-like peptide 5 (INSL5): free C-terminus is essential for RXFP4 receptor binding and activation. Biochemistry 50:8352-8361

Bellet D, Lavaissiere L, Mock P, Laurent A, Sabourin JC, Bedossa P, Le Bouteiller P, Frydman R, Troalen F, Bidart J (1997) Identification of pro-EPIL and EPIL peptides translated from insulinlike 4 (INSL4) mRNA in human placenta. J Clin Endocrinol Metab 82:3169-3172

Binder C, Binder L, Gurlit L, Einspanier A (2001) High serum concentrations of relaxin correlate with dissemination of breast cancer. In: Tregear GW, Ivell R, Bathgate RA, Wade JD (eds) Relaxin 2000. Kluwer Academic Publishers, Netherlands, 2001, 423-432

Binder C, Hagemann T, Husen B, Schulz M, Einspanier A (2002) Relaxin enhances in-vitro invasiveness of breast cancer cell lines by up-regulation of matrix metalloproteases. MHR: Basic Science of Reproductive Medicine 8:789-796. doi:10.1093/molehr/8.9.789

Binder C, Simon A, Binder L, Hagemann T, Schulz M, Emons G, Trumper L, Einspanier A (2004) Elevated concentrations of serum relaxin are associated with metastatic disease in breast cancer patients. Breast Cancer Res Treat 87:157-166. doi:10.1023/b:brea.0000041622.30169.16

Brener SHL, Schoenfeld C, Amelar RD, Dubin L, Weiss G. (1984) Stimulation of human sperm cervical mucus penetration in vitro by relaxin. Fertil Steril 42:92-96

Büllesbach EE, Schwabe C (2000) The relaxin receptor-binding site geometry suggests a novel gripping mode of interaction. J Biol Chem 275:35276-35280. doi:10.1074/jbc.M005728200

Büllesbach EE, Schwabe C (2002) The primary structure and the disulfide links of the bovine relaxin-like factor (RLF). Biochemistry 41:274-281. doi:10.1021/bi0117302

Büllesbach EE, Schwabe C (2001) Synthesis and conformational analysis of the insulin-like 4 gene product: Authors' affiliations. J Pept Res 57:77-83

Burger LL, Sherwood OD (1998) Relaxin increases the accumulation of new epithelial and stromal cells in the rat cervix during the second half of pregnancy. Endocrinology 139:3984-3995. doi:10.1210/en.139.9.3984

Chan LJ, Hossain MA, Samuel CS, Separovic F, Wade JD (2011) The relaxin peptide family--structure, function and clinical applications. Protein Pept Lett 18:220-229

Conrad KP, Novak J (2004) Emerging role of relaxin in renal and cardiovascular function. Am J Physiol Regul Integr Comp Physiol 287:250-261. doi:10.1152/ajpregu.00672.2003

Dschietzig T, Bartsch C, Baumann G, Stangl K (2006) Relaxin-a pleiotropic hormone and its emerging role for experimental and clinical therapeutics. Pharm Ther 112:38-56. doi:10.1016/j.pharmthera.2006.03.004 
Eigenbrot C, Randal M, Quan C, Burnier J, O'Connell L, Rinderknecht E, Kossiakoff AA (1991) X-ray structure of human relaxin at 1.5 A. Comparison to insulin and implications for receptor binding determinants. J Mol Biol 221 (1):15-21

Eppel W, Kucera E, Bielglmyer C (1999) Relationship of serum levels of endogenous relaxin to cervical size in the second trimester and to cervical ripening at term. Br Journal Obstet Gynaecol 106:917-923

Failli P, Nistri S, Quattrone S, Mazzetti L, Bigazzi M, Sacchi TB, Bani D (2002) Relaxin up-regulates inducible nitric oxide synthase expression and nitric oxide generation in rat coronary endothelial cells. FASEB J 16:252-254

Feng S, Agoulnik IU, Bogatcheva NV, Kamat AA, Kwabi-Addo B, Li R, Ayala G, Ittmann MM, Agoulnik AI (2007) Relaxin promotes prostate cancer progression. Clinical Cancer Res 13:1695-1702. doi:10.1158/1078-0432.ccr-06-2492

Feng S, Agoulnik A (2011) Expression of LDL-A module of relaxin receptor in prostate cancer cells inhibits tumorigenesis. Int J Oncol 39:1559-1565

Ferlin A, Pepe A, Gianesello L, Garolla A, Feng S, Facciolli A, Morello R, Agoulnik AI, Foresta C (2009) New Roles for INSL3 in Adults. Ann NY Acad Sci 1160:215-218. doi:10.1111/j.1749. 6632.2008.03787.x

Friedman A (2003) Remembrance: The contributions of Frederick Hisaw. J Clin Endocrinol Metab 88:524-527. doi:10.1210/jc.2002-021457

Gunnersen JM, Roche PJ, Tregear GW, Crawford RJ (1995) Characterization of human relaxin gene regulation in the relaxin-expressing human prostate adenocarcinoma cell line LNCaP.FGC. J Mol Endocrinol 15:153-166. doi:10.1677/jme.0.0150153

Hansell DJ, Bryant-Greenwood GD, Greenwood FC (1991) Expression of the human relaxin H1 gene in the decidua, trophoblast, and prostate. J Clin Endocrinol Metab 72:899-904. doi:10.1210/jcem72-4-899

Hisaw F (1926) Experimental relaxation of the pubic ligament of the guinea pig. Proc Soc Exper Biol Med 661-663.

Hombach-Klonisch S, Bialek J, Trojanowicz B, Weber E, Holzhausen HJ, Silvertown JD; Summerlee AJ, Dralle H, Hoang-Vu C, Klonisch T (2006) Relaxin enhances the oncogenic potential of human thyroid carcinoma cells. Am J Pathol 169:617-632. doi:10.2353/ajpath.2006.050876

Hossain MA, Bathgate RA, Kong C, Shabanpoor F, Zhang S, Haugaard-Jönsson LM, Rosengren KJ, Tregear GW, Wade JD (2008) Synthesis, conformation and receptor binding activity of human insulin-like peptide 5 (INSL5). ChemBioChem 9: 1816-1822.

Hossain MA, Samuel CS, Binder C, Hewitson TD, Tregear GW, Wade, JD, Bathgate RAD (2010) The chemically synthesized human relaxin-2 analog, B-R13/17K H2, is an RXFP1 antagonist. Amino Acids 39:409-416. doi:10.1007/s00726-009-0454-1

Hossain MA, Chow BSM, Zhao C, Xu Q, Du XJ, Wade JD, Samuel CS (2011) H3 relaxin demonstrates antifibrotic properties via the RXFP1 receptor. Biochemistry 50: 1368-1375. doi:10.1021/bi1013968

Hossain MA, Wade JD (2010) The roles of the A- and B-chains of human relaxin-2 and -3 on their biological activity. Curr Protein Pept Sci 11:719-724

Hsu SY (1999) Cloning of two novel mammalian paralogs of relaxin/insulin family proteins and their expression in testis and kidney. Mol Endocrinol 13:2163-2167. doi:10.1210/me.13.12.2163

Hsu SY, Nakabayashi K, Nishi S, Kumagai J, Kudo M, Sherwood OD, Hsueh AJW (2002) Activation of orphan receptors by the hormone relaxin. Science 295:671-674

Hwang JJ, Shanks RD, Sherwood OD (1989) Monoclonal antibodies specific for rat relaxin. IV. Passive immunization with monoclonal antibodies during the antepartum period reduces cervical growth and extensibility, disrupts birth, and reduces pup survival in intact rats. Endocrinology 125:260266. doi:10.1210/endo-125-1-260

Ivell R, Hunt N, Khan-Dawood F, Dawood MY (1989) Expression of the human relaxin gene in the corpus luteum of the menstrual cycle and in the prostate. Mol Cellular Endocrinol 66:251-255. doi:10.1016/0303-7207(89)90037-3

Ivell R, Hartung S, Anand-Ivell, R (2005) Insulin-like factor 3: Where are we now? Ann NY Acad Sci 1041:486-496. doi:10.1196/annals.1282.073

Jadeski LC, Chakraborty C, Lala PK (2003) Nitric oxide-mediated promotion of mammary tumour cell migration requires sequential activation of nitric oxide synthase, guanylate cyclase and mitogenactivated protein kinase. International journal of cancer 106:496. doi:10.1002/ijc.11268

Jadeski LC, Hum KO, Chakraborty C, Lala PK (2000) Nitric oxide promotes murine mammary tumour growth and metastasis by stimulating tumour cell migration, invasiveness and angiogenesis. Int $\mathbf{J}$ Cancer 86:30-39. doi:10.1002/(sici)1097-0215(20000401)86:1<30::aid-ijc5>3.0.co;2-i 
Johnson MR, Abdalla H, Allman AC, Wren ME, Kirkland A, Lighman SL (1991) Relaxin levels in ovum donation pregnancies. Fertil Steril 56:59-61

Kamat AA, Feng S, Agoulnik IU, Kheradmand F, Bogatcheva NV, Coffey D, Sood AK, Agoulnik AI (2006) The role of relaxin in endometrial cancer. Cancer Biol Therap 5:71-77. doi:10.4161/cbt.5.1.2289

Kawamura K, Kumagai J, Sudo S, Chun SY, Pisarska M, Morita H, Toppari J, Fu P, Wade JD, Bathgate RAD, Hsueh AJ (2004) Paracrine regulation of mammalian oocyte maturation and male germ cell survival. Proc Natl Acad Sci USA 101:7323-7328. doi:10.1073/pnas.0307061101

Kong RCK, Shiling PJ, Lobb DK, Gooley PR, Bathgate RAD (2010) Membrane receptors: Structure and function of the relaxin family peptide receptors. Mol Cell Endocrinol 320:1-15. doi:10.1016/j.mce.2010.02.003

Kumagai J, Hsu SY, Matsumi H, Roh JS, Fu P, Wade JD, Bathgate RAD, Hsueh AJ (2002) INSL3/Leydig insulin-like peptide activates the LGR8 receptor important in testis descent. J Biol Chem 277:31283-31286. doi:10.1074/jbc.C200398200

Laurent A, Rouillac C, Delezoide AL, Giovangrandi Y, Vekemans M, Bellet D, Abitbol M, Vidaud M (1998) Insulin-like 4 (INSL4) gene expression in human embryonic and trophoblastic tissues. Mol Reprod Dev 51:123-129. doi:10.1002/(sici)1098-2795(199810)51:2<123::aid-mrd1>3.0.co 2-s

Liang WC, Wu X, Peale FV, Lee CV, Meng YG, Gutierrez J, Fu L, Malik AK, Gerber HP, Ferrara N, Fuh G (2006) Cross-species vascular endothelial growth factor (VEGF)-blocking antibodies completely inhibit the growth of human tumor xenografts and measure the contribution of stromal VEGF. J Biol Chem 281:951-961. doi:10.1074/jbc.M508199200

Lin F, Otvos L Jr, Kumagai J, Tregear GW, Bathgate RA, Wade JD (2004) Synthetic human insulin 4 does not activate the G-protein-coupled receptors LGR7 or LGR8. J Pept Sci 10:257-264. doi:10.1002/psc.521

Liu C, Eriste E, Sutton S (2003) Identification of relaxin-3/INSL7 as an endogenous ligand for the orphan G-protein-coupled receptor GPCR135. J Biol Chem 278:50754-50764. doi:10.1074/jbc.M308995200

Liu C, Lovenberg T (2008) Relaxin-3, INSL5, and their receptors. Orphan G protein-coupled receptors and novel neuropeptides. Results Probl Cell Differ 46:213-237. doi:10.1007/400_2007_055

Lok S, Johnston DS, Conklin D, Lofton-Day CE, Adams RL, Jelmberg AC, Whitmore TE, Schrader S, Grisworld MD, Jaspers SR (2000) Identification of INSL6, a new member of the insulin family that is expressed in the testis of the human and rat. Biol Reprod 62:1593-1599. doi:10.1095/biolreprod62.6.1593

Lu CX, Walker WH, Sun J, Weisz OA, Gibbs RB, Witchel SF, Sperling MA, Menon RK (2006) Insulinlike peptide 6: Characterization of secretory status and posttranslational modifications. Endocrinology 147:5611-5623. doi:10.1210/en.2006-0503

Luo X, Bathgate RAD, Zhang W-J, Liu Y-L, Shao X-X Wade JD, Guo Z-Y (2010) Design and recombinant expression of insulin-like peptide 5 (INSL5) precursors and the preparation of mature human INSL5. Amino Acids 39: 1343-1352.

Ma S, Gundlach AL(2007) Relaxin-family peptide and receptor systems in brain: Insights from recent anatomical and functional studies. Adv Exp Med Biol 612:119-137. doi:10.1007/978-0-387-746722_9

McGowan BM, Stanley SA, Smith KL, White NE, Connolly MM, Thompson EL, Gardiner JV, Murphy KG, Ghatei MA, Bloom SR (2005) Central relaxin-3 administration causes hyperphagia in male Wistar rats. Endocrinology 146:3295-3300. doi:10.1210/en.2004-1532

Min G, Sherwood OD (1996) Identification of specific relaxin-binding cells in the cervix, mammary glands, nipples, small intestine, and skin of pregnant pigs. Biol Reprod 55:1243-1252. doi:10.1095/biolreprod55.6.1243

Montie J, Pienta K (1994) Review of the role of androgenic hormones in the epidemiology of benign prostatic hyperplasia and prostate cancer. Urology 43:892-899

Nomura A, Heilbrun LK, Stemmermann GN, Judd HL (1988) Prediagnostic serum hormones and the risk of prostate cancer. Cancer Res 48:3515-3517

O'Day MB, Winn RJ, Easter RA, Dzuik PJ, Sherwood OD (1989) Hormonal control of the cervix in pregnant gilts. II. Relaxin promotes changes in the physical properties of the cervix in ovariectomized hormone-treated pregnant gilts. Endocrinology 125:3004-3010. doi:10.1210/endo125-6-3004

Park J, Chang C, Hsu S (2005) New Insights into biological roles of relaxin and relaxin-related peptides. Rev Endocr Metab Disorders 6:291-296. doi:10.1007/s11154-005-6187-x

Pupula M, Quinn P, Maclennan A (1986) The effect of porcine relaxin on the fertilisation of mouse oocytes in vitro. Clin Reprod Fertil 4:383-387 
Sacchi TB, Bani D, Brandi ML, Falchetti A, Bigazzi M (1994) Relaxin influences growth, differentiation and cell-cell adhesion of human breast-cancer cells in culture. Int J Cancer 57:129-134. doi:10.1002/ijc.2910570123

Samuel CS, Unemori EN, Mookerjee I, Bathgate RAD, Layfield SL, Mak J, Tregear GW, Du X-J (2004) Relaxin modulates cardiac fibroblast proliferation, differentiation, and collagen production and reverses cardiac fibrosis in vivo. Endocrinology 145:4125-4133. doi:10.1210/en.2004-0209

Samuel CS (2005) Relaxin: Antifibrotic properties and effects in models of disease. Clin Med Res 3:241249

Samuel CS, Du XJ, Bathgate RAD, Summers RJ (2006) 'Relaxin' the stiffened heart and arteries: The therapeutic potential for relaxin in the treatment of cardiovascular disease. Pharm Ther 112:529552. doi:10.1016/j.pharmthera.2005.05.012

Shabanpoor F, Separovic F, Wade JD (2009) The human insulin superfamily of polypeptide hormones. Vitam Horm 80:1-31. doi:10.1016/s0083-6729(08)00601-8

Shabanpoor F, Hughes RA, Zhang S, Bathgate RAD, Layfield S, Hossain MA, Tregear G W, Separovic F, Wade JD (2010) Effect of helix-promoting strategies on the LGR8 receptor activity of novel analogues of the B-chain of human insulin-like peptide 3, INSL3. Amino Acids 38:121-131. DOI: 10.1007/s00726-008-0219-2

Sherwood CD, O'Byrne EM (1974) Purification and characterization of porcine relaxin. Arch Biochem Biophys 160:185-196. doi:10.1016/s0003-9861(74)80025-1

Sherwood OD (2004) Relaxin's physiological roles and other diverse actions. Endocr Rev 25:205-234. doi:10.1210/er.2003-0013

Silvertown JD, Geddes BJ, Summerlee AJ (2003) Adenovirus-mediated expression of human prorelaxin promotes the invasive potential of canine mammary cancer cells. Endocrinology 144:3683-3691. doi:10.1210/en.2003-0248

Silvertown JD, Ng J, Sato T, Summerlee AJ, Medin JA (2006) H2 relaxin overexpression increases in vivo prostate xenograft tumor growth and angiogenesis. Int J Cancer 118:62-73. doi:10.1002/ijc.21288

Silvertown JD, Symes JC, Neschadim A, Nonaka T, Kao JCH, Summerlee AJ, Medin JA (2007) Analog of H2 relaxin exhibits antagonistic properties and impairs prostate tumor growth. FASEB J 21:754765. doi:10.1096/fj.06-6847com

Sokol RZ, Wang XS, Lechago J, Johnston PD, Swerdloff RS (1989) Immunohistochemical localization of relaxin in human prostate. J Histochem Cytochem 37:1253-1255. doi:10.1177/37.8.2666509

Teerlink JR, Metra M, Felker MG, Ponikowski P, Voors AA, Weatherley BD, Marmor A, Katz A, Grzybowski J, Unemori E, Teichman SL, Cotter G (2009) Relaxin for the treatment of patients with acute heart failure (Pre-RELAX-AHF): a multicentre, randomised, placebo-controlled, parallel-group, dose-finding phase IIb study. Lancet 373:1429-1439. doi:10.1016/s01406736(09)60622-x

Unemori EN, Amento EP (1990) Relaxin modulates synthesis and secretion of procollagenase and collagen by human dermal fibroblasts. J Biol Chem 265:10681-10685

Unemori EN, Pickford LB, Salles AL, Piercy CE, Grove BH, Erikson ME, Amento EP (1996) Relaxin induces an extracellular matrix-degrading phenotype in human lung fibroblasts in vitro and inhibits lung fibrosis in a murine model in vivo. J Clin Investig 98:2739-2745. doi:10.1172/jci119099

Vinall RL, Tepper CG, Shi XB, Xue LA, Gandour-Edwards R, de Vere White RW (2006) The R273H p53 mutation can facilitate the androgen-independent growth of LNCaP by a mechanism that involves $\mathrm{H} 2$ relaxin and its cognate receptor LGR7. Oncogene 25:2082-2093

Weiss G (1989) Relaxin in the male. Biol Reprod 40:197. doi:10.1095/biolreprod40.2.197

Wilkinson T (2005) Coevolution of the relaxin-like peptides and their receptors. Ann NY Acad Sci 1041:534-539. doi:10.1196/annals.1282.080

Willcox J, Summerlee A (2010) RLN2 and its role in cancer. In: Huret J (ed) Atlas of Genetics and Cytogenetics in Oncology and Haematology. INIST-CNRS, France, pp 1768-3262

Winn RJ, Baker MD, Merle CA, Sherwood OD (1994) Individual and combined effects of relaxin, estrogen, and progesterone in ovariectomized gilts. II. Effects on mammary development. Endocrinology 135:1250-1255. doi:10.1210/en.135.3.1250

Zhang W-J, Luo X, Liu Y-L, Shao X-X, Wade JD, Bathgate RAD, Guo Z-Y (2012) Site-specific DOTA/europium-labeling of the recombinant human relaxin-3 for receptor-ligand interaction. Amino Acids 43: 983-992.

Zhu J, Kuei C, Sutton S, Kamme F, Yu J, Bonaventure P, Atack J, Lovenberg TW, Liu C (2008) Identification of the domains in RXFP4 (GPCR142) responsible for the high affinity binding and agonistic activity of INSL5 at RXFP4 compared to RXFP3 (GPCR135). Eur J Pharmacol 590:4352. doi:10.1016/j.ejphar.2008.05.025 
Ziel HK (2000) Historical Note Frederick L. Hisaw (1891-1972) and the discovery of relaxin. The Endocrinologist 10:215218. doi:10.1097/00019616-200010040-00001 


\section{Table I}

Table I: Summary of recognized functions of relaxin peptide subfamily members, performing roles undertaken by specific peptide hormones in humans unless otherwise specified. See text for specific references.

\begin{tabular}{|c|c|}
\hline Peptide Hormone & Functions \\
\hline Relaxin (relaxin-2) & $\begin{array}{l}\text { - } \text { aids embryo implantation via uterine vascularisation } \\
\text { and differentiation of endometrial cells } \\
\text { - } \\
\text { - } \text { pperm motility in male reproductive system } \\
\text { - } \text { increased vascularisation and renal functions in } \\
\text { pregnant females, lead to haemodynamic roles in } \\
\text { acute heart failure patients (Phase III clinical trials) } \\
\text { - produced by cancer cells and acts on its receptor } \\
\text { (autocrine signalling) to promote cancer growth and } \\
\text { metastasis }\end{array}$ \\
\hline Relaxin-3 & $\begin{array}{l}\text { - regulation of energy homeostasis and appetite } \\
\text { regulation }\end{array}$ \\
\hline INSL3 & $\begin{array}{ll}\text { - } & \text { involved in testicular descent } \\
\text { - } & \text { regulates germ cell maturation }\end{array}$ \\
\hline INSL4 & - $\quad$ possibly involved in trophoblastic development \\
\hline INSL5 & - $\quad$ associated with feeding functions \\
\hline INSL6 & - involved in spermatogenesis progression \\
\hline
\end{tabular}




\section{FIGURES.}

\section{Figure legends}

Figure 1: Schematic showing the different members within the insulin-relaxin superfamily of peptide hormones and their corresponding receptors. *receptors for INSL4 and INSL6 remain unknown

Figure 2: Sequence homology of members within the human insulin-relaxin superfamily of peptide hormones. Conserved cysteines highlighted in blue denote the intra-molecular disulfide bond within the A-chain; yellow and green inter-disulfide between A- and B-chains, respectively. Glycines highlighted in mauve denote conserved residues unique to the B-chain.

Figure 3: Representation of post-translational modifications undergone by single-chain pre-prohormone to its active heterodimeric stage. Signal peptide in pre-prohormones leads the transport of the peptide from the ribosomal ubiquitins. Following the loss of signal peptide, the pre-prohormone is converted to a prohormone via co-translational modifications. Proteolytic cleavage of C-chain then yields the A- and B- chain combination, forming mature, active 2-chain heterodimeric peptide.

Figure 4: Molecular representations of native human relaxin-2 (A) and its analogue H2 B-R-13/17K with Arg $_{13}$ and $\mathrm{Arg}_{17}$ of the native H2 B-chain mutated to lysines (B). The H2 B-R13/17K analogue has demonstrated antagonistic properties towards the relaxin native receptor, reducing the cancer growth and metastasis in both in vitro and in vivo studies (Silvertown et al. 2007; Hossain et al. 2009). 


\section{FIGURE 1}

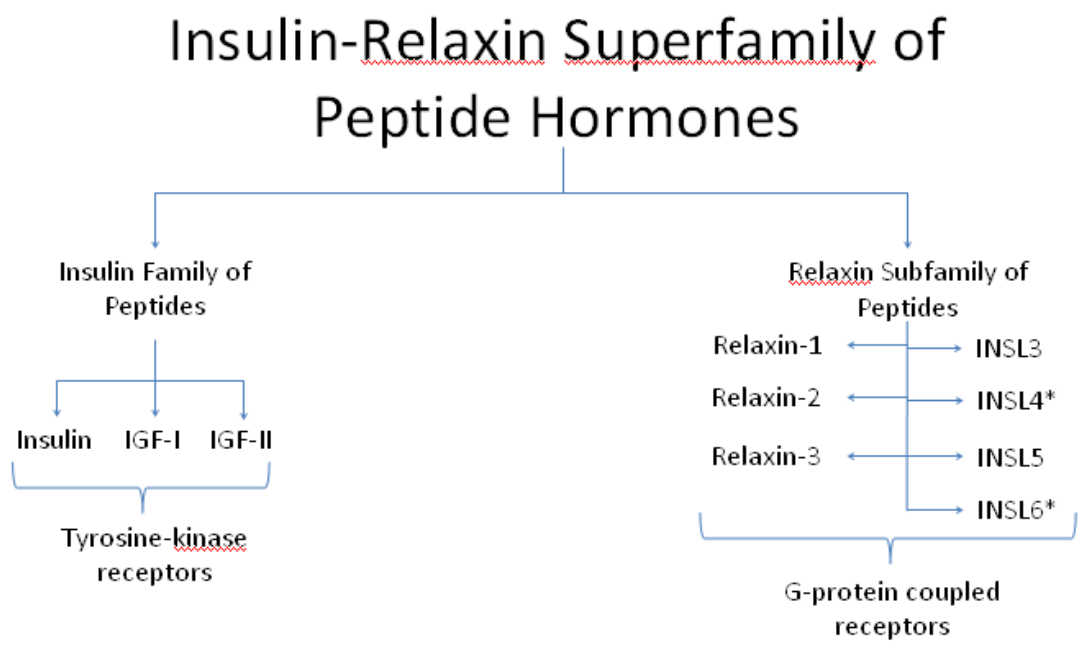




\section{FIGURE 2}

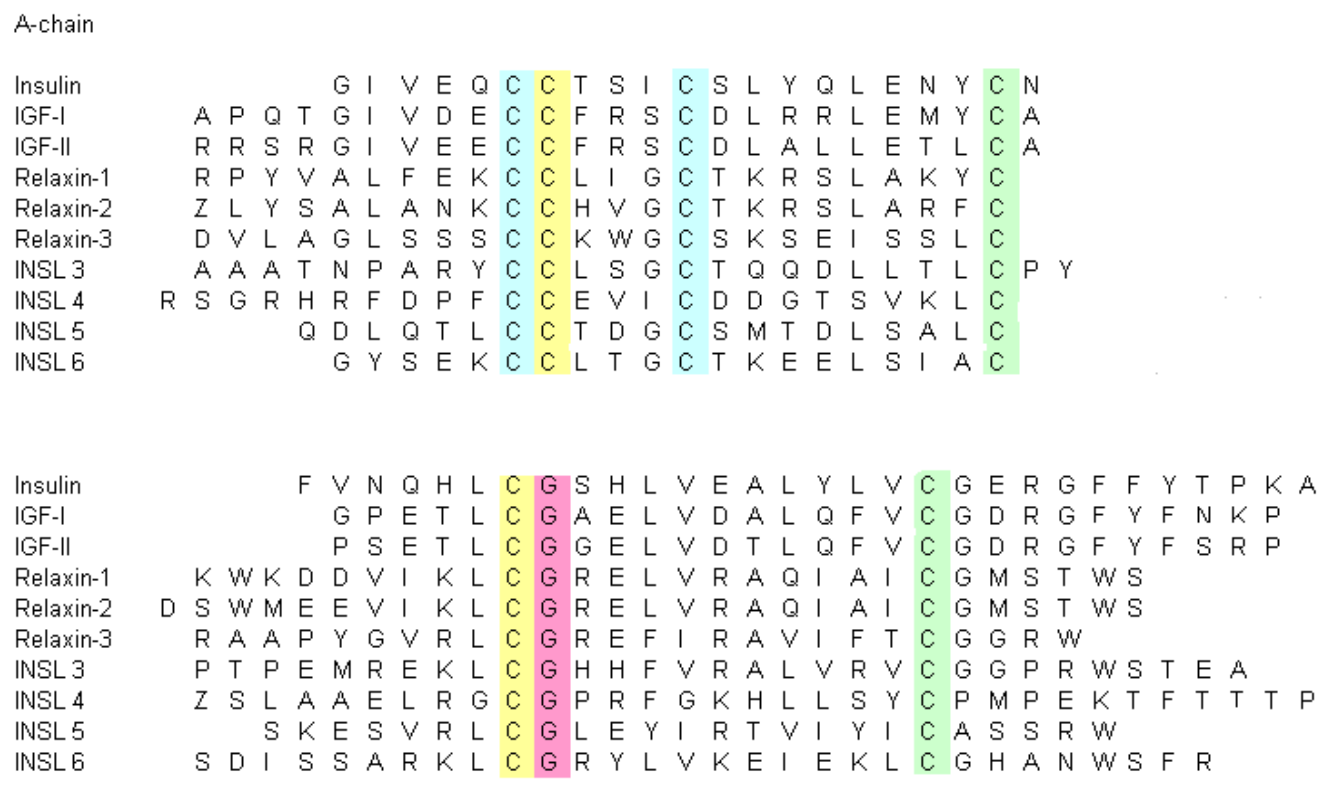

B-chain 


\section{FIGURE 3}

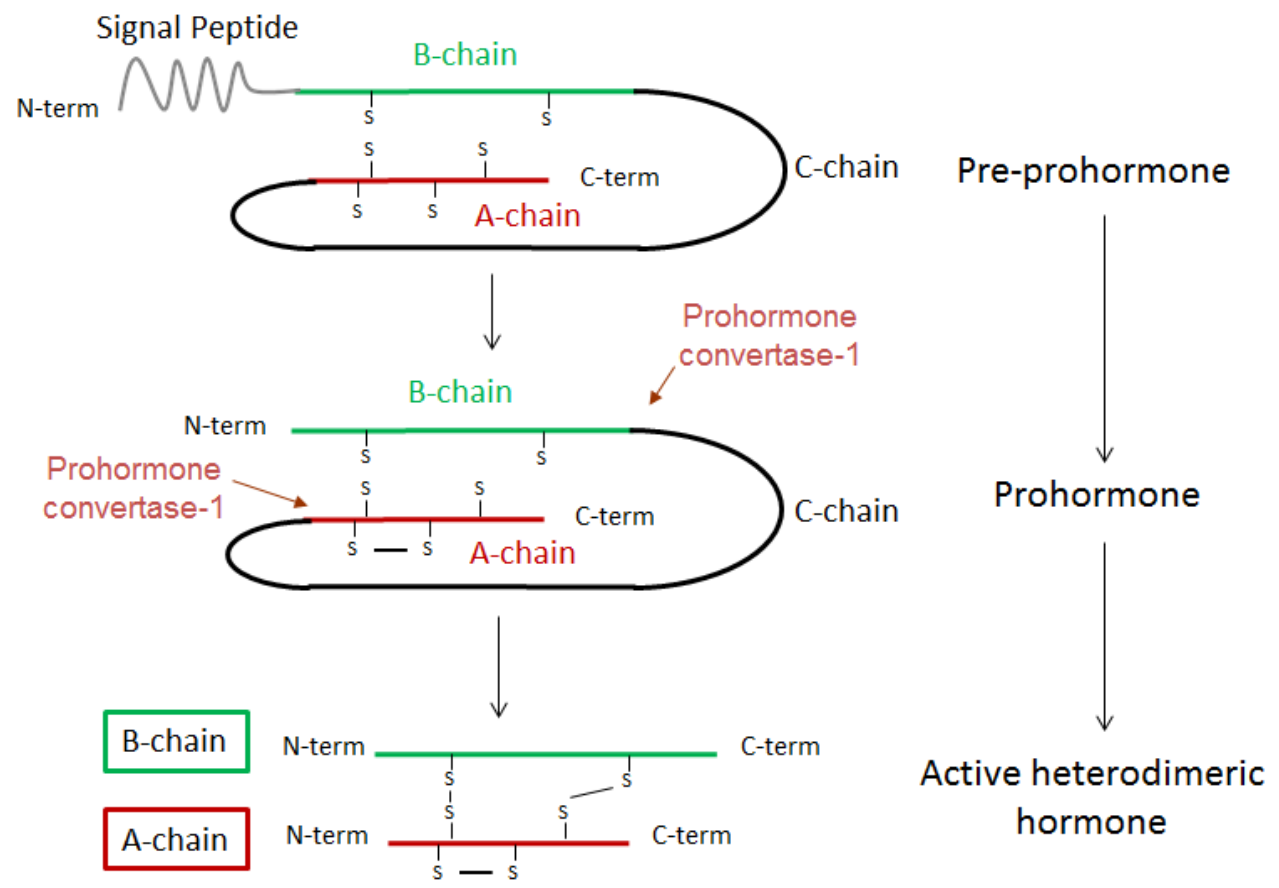




\section{FIGURE 4}

A:

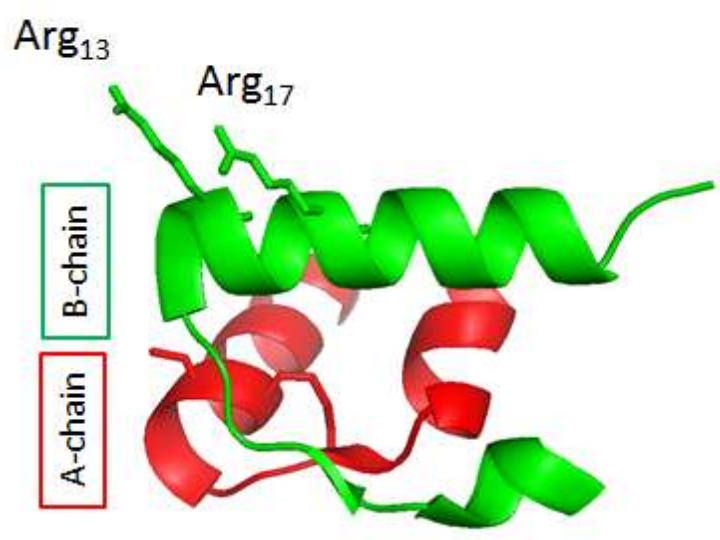

Native $\mathrm{H} 2$ relaxin

B:

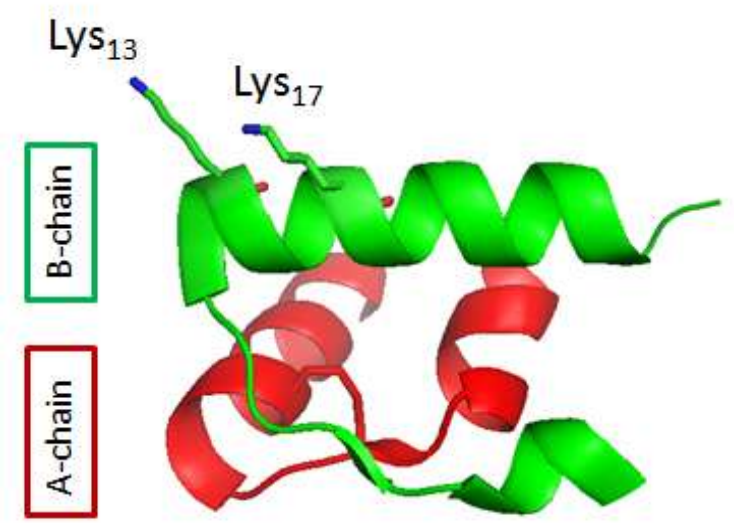

H2 B-R13/17K analog 